\title{
Why and how to support depsychiatrisation of adult transidentity in ICD-11: A French study
}

\author{
Françoise Askevis-Leherpeux ${ }^{\mathrm{a}, \mathrm{b}, *}$, Marie de la Chenelière ${ }^{\mathrm{a}, \mathrm{c}, \mathrm{d}}$, Antoine Baleige $^{\mathrm{a}}$, \\ Sarah Chouchane ${ }^{a}$, Marie-Jeanne Martinc ${ }^{c}$, Rebeca Robles-García ${ }^{e}$, Ana Fresán $^{\mathrm{e}}$, \\ Alexandre Quach ${ }^{\mathrm{a}}$, Anne-Claire Stona ${ }^{\mathrm{a}}$, Geoffrey Reed ${ }^{\mathrm{e}, \mathrm{f}}$, Jean-Luc Roelandt ${ }^{\mathrm{a}, \mathrm{b}}$ \\ a EPSM Lille-Métropole, WHOCC for Research and Training in Mental Health, 211 rue Roger Salengro, 59260 Hellemmes, Franc \\ ${ }^{\mathrm{b}}$ Equipe INSERM - ECEVE (UMR 1123), 75011 Paris, France \\ ${ }^{\mathrm{C}}$ Maison Dispersée de Santé, 167 Rue d'Arras, 59000 Lille, France \\ d Association Nationale Transgenre (Transgender National Association), 54097 Nancy, France \\ e National Institute of Psychiatry "Ramón de la Fuente Muñiz", Calz México-Xochimilco 101, Huipulco, 14370 Tlalpan, Mexico City, Mexico \\ ${ }^{\mathrm{f}}$ World Health Organisation, 1211 Geneva, Switzerland
}

\section{A R T I C L E I N F O}

\section{Article history:}

Received 17 December 2018

Received in revised form 27 March 2019

Accepted 30 March 2019

Available online 10 April 2019

\section{Keywords:}

International Classification of Diseases

Transgender identity

Depsychiatrisation

Clinical protocols

Health policy

Human rights

\begin{abstract}
A B S T R A C T
Background: For the 11th version of the International Classification of Diseases, the WHO recommended to rename transgender transidentity as "gender incongruence", to remove it from the chapter of mental and behavioral disorders, and to put it in a new category titled "Conditions related to sexual health". This should contribute to reduce stigmatisation while maintaining access to medical care. One argument in favor of depsychiatrisation is to demonstrate that essential features of gender identity disorders, namely psychological distress and functional impairment, are not necessarily reported by every transgender person, and may result from social rejection and violence rather than dysphoria itself. Initially confirmed in Mexico, these hypotheses were tested in a specific French medical context, where access to care does not require any prior mental health evaluation or diagnosis.

Method: In 2017, 72 transgender persons completed retrospective interviews which focused on the period when they became aware that they might be transgender and perhaps would need to do something about it. Results: Results showed that psychological distress and functional impairment were not reported by every participant, that they may result from rejection and violence, and especially from rejection and violence coming from coworkers and schoolmates. Additional data showed that the use of health services for body transformation did not depend on distress and dysfunction. Finally, participants preferred ICD 11 to employ "transgender" or "transidentity" rather than "gender incongruence".

Conclusion: Results support depsychiatrisation. They are discussed in terms of medical, ethical, legal, and social, added values and implications of depsychiatrisation.

(C) 2019 The Authors. Published by Elsevier Masson SAS. This is an open access article under the CC BY-NC-
\end{abstract} ND license (http://creativecommons.org/licenses/by-nc-nd/4.0/).

\section{Introduction}

\subsection{Context}

In the still relevant version of ICD (ICD10, F64*; Gender Identity Disorders), transgenderism is considered a mental illness, including a large spectrum of disorders. This raises two main challenges in dayto-day practice. First, the label of mental illness itself is a source of stigmatisation, which, in turn, affects transgender health [1]. Second, in almost all countries, access to care is dependent upon receiving an official psychiatric diagnosis. This raises questions about the ethics of

\footnotetext{
* Corresponding author.

E-mail address: fleherpeux@epsm-lille-metropole.fr (F. Askevis-Leherpeux).
}

requiring psychiatric diagnoses before transgender people can obtain medical treatment and hormonal-chirurgical reassignment [2-4]. But to our knowledge, in some countries, including France, the medical process can be successfully engaged without considering a psychiatric diagnosis as a prerequisite.

Evidence that would support depsychiatrising would demonstrate that essential features of gender identity disorders, namely psychological distress and functional impairment, are neither necessary nor sufficient. It was initially confirmed by Robles et al. [5] in Mexico, and then by Campbell et al. [6] in South-Africa, who observed that distress and dysfunction were not reported by everyone (no necessity) and were related more to experienced violence or rejection than to transgender identity itself (no sufficiency). Thus the aim of the research was to replicate the original Mexican study in a different cultural and medical context, specifically within a transgender 
population receiving transgender related care in a French primary care setting independent from mental health services.

\subsection{From ICD-10 to ICD-11}

In the tenth revision of the International Classification of Diseases (ICD-10), "transgenderism" was named "transsexualism", defined as the desire to live and be accepted as a member of the opposite sex, and considered an example of "gender identity disorders" (for the evolution of the ICD, see [7,8]). For the ICD-11 version, the Department of Mental Health and Substance, in collaboration with the Department of Reproductive Health, suggested renaming transgender identity to "gender incongruence", to remove it from the chapter of mental and

behavioral disorders and to put it in a new category titled "Conditions related to sexual health" [7]. Reclassifying transgender diagnoses would be less stigmatising while maintaining access to medical care $[9,10]$.

In June 2018, the WHO publicly adopted this proposition, and abandoned "opposite sex" or "anatomic sex" in favor of "experienced gender" and "assigned sex". These changes reflect the evolution of clinical, theoretical, and social views. They also challenge the importance of language as a source of stigmatisation, including in the setting of scientific publications [11]. Moreover, because the ICD is an international standard and language is not free from culture, the labeling of categories must be questioned [12]. A direct translation from the English labeling might not be appropriate, and phrasing should be discussed with all stakeholders, especially transgender people.

\subsection{A multi-level stigmatisation: some French illustrations $[13,14]$}

Stigmatisation results not only from being a transgender person, but also from the psychiatrisation of the diagnosis. It can occur at both structural and interpersonal levels and may be internalized as self-stigmas [15]. Moreover, not only experiencing but also expecting rejection may have negative mental or psychological consequences $[16,17]$ and, as for most stigmatised minority groups, coping strategies are not always adaptive [18].

Considering transgenderism a mental health issue denies some human rights. For instance, in France, until the beginning of 2016, it was difficult to obtain a sex change from the courts, because this change was made on the basis of psychiatric and medical attestations, and was still based on a binary definition of transidentity. Moreover, courts may rule against transgender people in child custody cases on the basis of transgenderism being a mental disorder. Changing marital status was also difficult before the new law on marriage equality (2013), which opened marriage to samesex people, enabling transwomen or transmen to get married or to remain married with the same person after transition.

\subsection{Escaping psychiatry in the medical care process: a French innovative medical center}

The MDS (Maison Dispersée de Santé), located in Lille (France), supports transgender people in their transition process, in close collaboration with local associations. The core idea is to provide access to support and care, especially hormone therapy, without the need for a psychiatric diagnosis. This initiative started with people who were refused hormonal treatment by health services and resorted to self-medication. This pragmatic and innovative position gives MDS a pioneering position in the depsychiatrisation of transgenderism [19]. The number of users (16-80 years old) increased from 94 in September 2015 to 264 in February 2017, illustrating the success of the structure.

The care protocol at the MDS differs from the typical French protocol in several ways: there is no long diagnostic and prognostic evaluation phase and psychiatric follow-up is not required; there is no inclusion selection, and no obligation for the user to accept medical decisions. It is close to the WPATH's standards of care [20], in that it is respectful of the person. However, informed consent is sought by giving appropriate information related to own transition process. The people who come to request hormone therapy are considered like any others who submit a request for care. This does not extend to surgery access. In such a case, they have to conform to a hospital's protocol, or have surgery abroad if they have sufficient financial resources.

\subsection{Objectives}

One important issue in the debate regarding depsychiatrisation is the validity of diagnosis essential features, i.e. psychological distress and functional disability. As argued by some authors [21,22], and confirmed by others [5], even if these features are commonly experienced by transgender people, they are not universal and are reported only by a small portion of those seeking treatment $[23,24]$. Moreover, they can relate to factors other than trans-identity, in particular the social environment responsible for stigmatisation.

In this context, in line with the WHO's recommendations and in agreement with the work of Robles et al. [5], the main objective of this study was to examine in a specific psychiatry-free French context,

1 If all transgender people report having experienced psychological distress or functional disability (as ICD-10 requires).

2 If psychological distress and functional disability can result from factors other than gender identity, in particular rejection of, and violence against, transgender people.

The secondary objective was to examine whether the use of health care services for the transformation of the body was related to factors other than gender identity such as distress, dysfunction, rejection or violence.

Finally, new to this study, we examined the phrasing of gender change (for additional data, see [25]).

\section{Methods}

\subsection{Background}

The research program was conducted after a meeting organized at The French University "Paris-Sorbonne" (2010), with the participation of transgender people, representatives of transgender associations, members of the French WHO CC and members of the "Medicine, Science, Health and Society" research group. Communications were published in a special issue of L'information Psychiatrique (2011), titled Troubles liés au genre (gender related disorders) (see also [26]). Following this meeting, the project was monitored by a participative steering committee, the Trans Collective and the MDS. All participants received constant updates until the edition of the WHO CC report.

\subsection{Participants}

The study took place in 2017, before the release of the latest edition of the ICD (June 2018). Seventy-two people aged 18-50 volunteered and signed an informed consent. They were currently attending, or had until recently attended, the MDS.

\subsection{Materials}

\subsubsection{Main questionnaire}

The main questionnaire, available on request, was translated and adapted from the one used by Robles et al. [5] in Mexico. It included two types of questions: information about the population 
(sociodemographic data and history of gender identity) and retrospective questions about experiences of gender incongruence, rejection, violence, distress and dysfunction.

Retrospective questions referred to a given period of time, called the Index Period, during which gender incongruence, distress and dysfunction may have been particularly prominent [27]. It was defined as the age the participants became aware that they might be transgender and perhaps might need to do something about it. They were introduced as follows: "Now, I'm going to ask you a few questions about the particular feelings and thoughts you had at this time (Index Period). I am not asking how you feel or think now, but how you remember you felt or thought during that particular time in your life. Do not try to interpret your experience through what you know and what has happened to you since then; just try to tell me about your thoughts and feelings at that time". The participants were questioned on the following topics:

- Gender category: Current identity, Birth category.

- Use of health care services

- Trans-identity (dichotomous answers and/or ratings): Experience of discomfort due to secondary sexual characteristics, changes made to become closer to the desired gender, and desire to be considered a member of that gender.

- Psychological distress: experience and intensity, and means used to face it.

- Functional disability : experience and intensity [28], across three domains: family, social, work or school

- Social Rejection and Violence related to gender identity, and from whom

\subsubsection{Additional question}

"According to you, which terms would best designate gender change?"

\subsection{Statistical analyses}

Sixty-nine participants were included in analyses. The remaining three, defined themselves as queer, i.e. outside of binary gender categorization, were too few to be considered as a group.

Descriptive statistics were calculated, and Chi-square analyses or independent sample t-tests were used for comparison purposes. Analyses were performed with SPSS-X version 20 for Windows.

\section{Results}

\subsection{Population}

The mean age of the sample was $27.7(\mathrm{SD}=9.6$, range $=18-50)$ years, with more than half of the participants having been assigned a male sex at birth $(60.9 \% ; n=42)$. At the time of the study, $73.9 \%$ $(n=51)$ were single, $37.7 \%(n=26)$ were gainfully employed and $31.9 \%(n=22)$ were full-time students.

As seen in Table 1, on average, participants reported they first became aware of their transgender identity and considered their options for gender transition at 9.2 years of age, and were aware of secondary sex characteristics at 12.8 years of age. A high percentage of participants reported having used some health service for body transformation at some point in their lives $(82.6 \% ; n=57)$. Among these, all received hormone treatment, initiated at an average age of 24.8 years, and $91.2 \%$ $(\mathrm{n}=52)$ with medical supervision. Only $33.3 \%(\mathrm{n}=23)$ reported having received surgery, the first one reported at age of 27.3 years. Compared with transwomen, transmen reported younger ages when they received hormone treatment $\left(M=21.2\right.$, vs. $M=27.3$ years; $\left.t_{(67)}=2.9, p=0.005\right)$ and surgery $\left(M=23.1\right.$ vs. $M=31.2$ years, $\left.t_{(67)}=2.3, p=0.03\right)$.
Participants reported having experienced an intense level of desire to be a different gender than the one assigned at birth, $\mathrm{M}=4.8$ ( $\mathrm{SD}=1.0$; range $3-6)$, where a score of 6 represents the most intense level. All participants reported discomfort with several aspects of their bodies and a desire to make a variety of changes to make themselves more similar to their desired gender (Table 2). More participants assigned a female sex at birth, compared to those assigned a male one, expressed discomfort with voice $\left(\chi_{(1)}^{2}=6.9, \quad \mathrm{p}=0.008\right.$, Fisher $\left.=0.01\right)$, hips $\left(\chi_{(1)}^{2}=22.1\right.$, $\mathrm{p}<0.001$, Fisher $<0.001)$ and chest $\left(\chi_{(1)}^{2}=20.7, \mathrm{p}<0.001\right.$, Fisher $<0.001)$ and changed their way of dress $\left(\chi_{(1)}^{2}=4.3, p=0.03\right.$, Fisher $=0.04$ ), while more participants assigned a male sex at birth, compared to those assigned a female one, expressed discomfort with pubic hair $\chi_{(1)}^{2}=6.8, p=0.009$, Fisher $=0.01$ ).

\subsection{Experience of social rejection and violence}

More than half of the participants $(55.1 \%, \mathrm{n}=38)$ reported having experienced social rejection related to their gender identity during the index period, most commonly by schoolmates or coworkers $(71.0 \%$, $\mathrm{n}=27)$, followed by family members $(57.8 \%, \mathrm{n}=22)$ and friends $(26.3 \%$, $\mathrm{n}=10$ ). The most common form of rejection from family members and friends was being treated with indifference or being ignored (31.8\%, $n=7$ and $44.4 \%, n=4$ ), while rejection by schoolmates or coworkers was with verbal or physical aggression $(37.5 \%, n=9)$.

Violence related to their gender identity was experienced by $46.4 \%(n=32)$ of the participants. Among these, all reported having suffered psychological violence, followed by physical violence $(53.1 \%, n=17)$ and sexual violence $(28.1 \%, n=9)$. Economic and workplace/school violence were the least frequently reported (25.0\%; $n=8$ for each). Violence was mostly perpetrated by family members $(53.1 \%, \mathrm{n}=17$ ) or by a person well known to the participant (friend, colleague, neighbor) $(40.6 \%, n=13)$.

A similar proportion of transwomen and transmen reported having experienced social rejection in general $(54.8 \%, \mathrm{n}=23$ vs $\left.55.6 \%, \mathrm{n}=15 ; \chi_{(1)}^{2}=0.004, \mathrm{p}=0.94\right)$ and violence $(47.6 \%, \mathrm{n}=20 \mathrm{vs}$. $\left.44.4 \%, \mathrm{n}=12 ; \chi^{2}(1)=0.06, \mathrm{p}=0.79\right)$. More transmen experienced rejection from friends than did transwomen $(25.9 \%, \mathrm{n}=7$ vs $7.1 \%$, $\mathrm{n}=3 ; \chi_{(1)}^{2}=4.6, \mathrm{p}=0.03$, Fisher $\left.=0.04\right)$.

\subsection{Gender identity, use of health services, violence and rejection based on distress and functional disabilities}

A high percentage of participants $(88.4 \%, n=61)$ reported having experienced psychological distress related to their gender identity. Among those participants, the most common reports of distress included depressive symptoms $(72.1 \%, n=44)$, suicide ideation or attempt $(37.7 \%, \mathrm{n}=23)$ and symptoms of anxiety $(36.1 \%$, $\mathrm{n}=22$ ). On a scale from 0 to 100 , the average level of distress among those who reported it was high $(\mathrm{M}=78.2, \mathrm{SD}=16.9$; range $30-100)$. A total of $23.0 \%(n=14)$ of those who experienced distress reported distancing themselves from others, and $21.3 \%(n=13)$ engaging in self-destructive behaviors (fighting, abusing substances, and attempting suicide). Only $36.1 \%(n=22)$ reported having received specialized psychological or psychiatric treatment, and half of these $(n=11)$ found the treatment to be beneficial. Differences between participants who reported and those who did not report distress associated with their gender identity are shown in Table 3.

A similar proportion of transmen $(96.3 \% ; n=26)$ and transwomen $(83.3 \% ; n=35)$ reported having experienced distress. A higher proportion of male sex at birth participants who experienced discomfort with facial/body hair reported distress. Also, participants who reported distress had significantly higher levels of work/scholastic dysfunction.

Dysfunction related to experienced gender identity was reported by $85.5 \%(n=59)$ of the sample. Social and work/scholastic 
Table 1

Demographic features, use of health services for body transformation and ages related to transidentity and body transformation according to current gender identity (Women vs. Men).

\begin{tabular}{|c|c|c|c|}
\hline & $\begin{array}{l}\text { Total Sample } \\
(\mathrm{n}=69)\end{array}$ & $\begin{array}{l}\text { Women/ } \\
\text { Transwomen } \\
(\mathrm{n}=42)\end{array}$ & $\begin{array}{l}\text { Men/Transmen } \\
(\mathrm{n}=27)\end{array}$ \\
\hline & \multicolumn{3}{|c|}{ Mean (SD; Range) } \\
\hline Age (Years) & $\begin{array}{l}27.7(9.7 ; 18- \\
50)\end{array}$ & $\begin{array}{l}30.8 ;(11.0 ; 18- \\
50)\end{array}$ & $\begin{array}{l}22.9(4.4 ; 18- \\
34)\end{array}$ \\
\hline Years of education & $\begin{array}{l}13.7(2.5 ; 9- \\
20) \\
n \%\end{array}$ & $14.0(2.5 ; 9-20)$ & $\begin{array}{l}13.3(2.4 ; 9- \\
18)\end{array}$ \\
\hline Employment status - paid & $2637.7 \%$ & $1638.1 \%$ & $1037.0 \%$ \\
\hline Marital status - Single & $5173.9 \%$ & $3173.8 \%$ & $2074.1 \%$ \\
\hline Body transformation - Yes & $5782.6 \%$ & $3378.6 \%$ & $2488.9 \%$ \\
\hline Hormonal treatment & $5782.6 \%$ & $3378.6 \%$ & $2488.9 \%$ \\
\hline Surgeries & $2333.3 \%$ & $1236.4 \%$ & $1145.8 \%$ \\
\hline & \multicolumn{3}{|c|}{ Mean (SD; Range) } \\
\hline $\begin{array}{l}\text { Age of first awareness of } \\
\text { transgender identity and } \\
\text { maybe } \\
\text { needing to do something } \\
\text { about it }\end{array}$ & $\begin{array}{l}9.2(3.9 ; 3- \\
17)\end{array}$ & $9.9(3.9 ; 3-17)$ & $\begin{array}{l}8.2(3.7 ; 3- \\
16)\end{array}$ \\
\hline $\begin{array}{l}\text { Age of first awareness of } \\
\text { secondary sex } \\
\text { characteristics }^{\mathrm{a}} \\
\text { (Interview index period) }\end{array}$ & $\begin{array}{l}12.8(2.0 ; 10- \\
20)(n=48)\end{array}$ & $\begin{array}{l}13.3(2.1 ; 11- \\
20)(n=26)\end{array}$ & $\begin{array}{l}12.2 ;(1.8 \\
10-17) \\
(n=22)\end{array}$ \\
\hline $\begin{array}{l}\text { Age at first hormonal } \\
\text { treatment }\end{array}$ & $\begin{array}{l}24.8(9.0 ; 14- \\
50)\end{array}$ & $\begin{array}{l}27.3(10.9 ; 14- \\
50\end{array}$ & $\begin{array}{l}21.2(3.6 ; 17- \\
28)\end{array}$ \\
\hline $\begin{array}{l}\text { Age at first surgery for body } \\
\text { transformation }\end{array}$ & $\begin{array}{l}27.3(9.2 ; 18- \\
50)(n=23)\end{array}$ & $\begin{array}{l}31.2(11.0 ; 18- \\
50)(\mathrm{n}=12)\end{array}$ & $\begin{array}{l}23.1(4.0 ; 18- \\
29)(n=11)\end{array}$ \\
\hline $\begin{array}{l}\text { Type of surgery (of those who } \\
\text { had received surgery) }\end{array}$ & $n \%(n=23)$ & $\mathrm{n} \%(\mathrm{n}=12)$ & $\mathrm{n} \%(\mathrm{n}=11)$ \\
\hline Mastectomy & $1147.8 \%$ & - & $11100 \%$ \\
\hline Breast implants & $730.4 \%$ & $758.3 \%$ & - \\
\hline Nose & $417.3 \%$ & $433.3 \%$ & - \\
\hline Hysterectomy & $417.3 \%$ & - & $436.3 \%$ \\
\hline Facial feminization & $313.0 \%$ & $325.0 \%$ & - \\
\hline Sexual reassignment & $313.0 \%$ & $325.0 \%$ & - \\
\hline Liposculpture & $28.6 \%$ & $216.6 \%$ & - \\
\hline Chin & $28.6 \%$ & $216.6 \%$ & - \\
\hline Adan's apple & $28.6 \%$ & $216.6 \%$ & - \\
\hline Forehead & $28.6 \%$ & $216.6 \%$ & - \\
\hline Capillary implants & $28.6 \%$ & $216.6 \%$ & - \\
\hline Ovarectomy & $28.6 \%$ & - & $218.1 \%$ \\
\hline Buttock implants & $28.6 \%$ & $18.3 \%$ & $19.0 \%$ \\
\hline Cheekbones & $14.3 \%$ & $18.3 \%$ & - \\
\hline Throat & $14.3 \%$ & $18.3 \%$ & - \\
\hline
\end{tabular}

Note: " Transwomen" refers to people whose sex assigned at birth was male and who made a transition to a female identity, and vice versa for "Transmen".

a Based on subjects whose first age of awareness of transgender identity was at the age of 12 or less.

dysfunction were the most frequently reported $(71.0 \%, n=49$ for each), while family dysfunction was reported by $44.9 \%(n=31)$ of individuals. Average level of dysfunction (10-point scale) was moderate for social dysfunction $(M=5.2 ; S D=3.4$; range $0-10)$ and work/scholastic dysfunction $(\mathrm{M}=4.9 ; \mathrm{SD}=3.3$; range $0-10)$ and low for family dysfunction $(\mathrm{M}=3.3, \mathrm{SD}=3.5$, range $0-10)$. Dysfunction attributed to gender identity was similarly reported by transwomen $(83.3 \% ; n=35)$ and transmen $(88.9 \%$; $n=24)$. Participants who experienced dysfunction also reported more experiences of rejection by schoolmates/coworkers.

A higher proportion of participants who used health services for body transformation had gainful employment, and asked to be referred to as the desired gender. Experiences of rejection, violence and level of dysfunction did not vary as a function of body transformation.

\subsection{Appropriate word(s) to designate gender change}

Analysis was focused on two aspects:
Table 2

Discomfort with body aspects and behavioral changes performed during interview index period to be more like the desired gender, according to assigned sex at birth.

\begin{tabular}{|c|c|c|c|}
\hline & 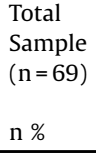 & $\begin{array}{l}\text { Assigned sex at } \\
\text { birth - Male } \\
\text { Transwomen } \\
(\mathrm{n}=42) \\
\mathrm{n} \%\end{array}$ & $\begin{array}{l}\text { Assigned sex at } \\
\text { birth - Female } \\
\text { Transmen } \\
(\mathrm{n}=27) \\
\mathrm{n} \%\end{array}$ \\
\hline \multicolumn{4}{|l|}{ Body area of discomfort } \\
\hline Genitals & $\begin{array}{l}50 \\
72.5 \%\end{array}$ & $3173.8 \%$ & $1970.4 \%$ \\
\hline Voice & $\begin{array}{l}43 \\
62.3 \%\end{array}$ & $2150.0 \%$ & $2281.5 \%$ \\
\hline Pubic hair & $\begin{array}{l}20 \\
29.0 \%\end{array}$ & $1740.5 \%$ & $311.1 \%$ \\
\hline Hips & $\begin{array}{l}23 \\
33.3 \%\end{array}$ & $511.9 \%$ & $1866.7 \%$ \\
\hline Chest & $\begin{array}{l}47 \\
68.1 \%\end{array}$ & $2047.6 \%$ & $27100.0 \%$ \\
\hline Hand or feet & $\begin{array}{l}12 \\
16.7 \%\end{array}$ & $921.4 \%$ & $311.1 \%$ \\
\hline $\begin{array}{l}\text { Facial hair (if birth-assigned } \\
\text { male) }\end{array}$ & - & $2457.1 \%$ & - \\
\hline $\begin{array}{l}\text { Body hair (if birth-assigned } \\
\text { male) }\end{array}$ & - & $2252.4 \%$ & - \\
\hline $\begin{array}{l}\text { Menstruation (if birth- } \\
\text { assigned female) }\end{array}$ & - & - & $2385.2 \%$ \\
\hline \multicolumn{4}{|c|}{ Behavioral changes performed to be more like the desired gender } \\
\hline $\begin{array}{l}\text { Attempting to change } \\
\text { physical appearance }\end{array}$ & $\begin{array}{l}52 \\
75.4 \%\end{array}$ & $2969.0 \%$ & $2385.2 \%$ \\
\hline Dressing differently & $\begin{array}{l}46 \\
66.7 \%\end{array}$ & $2457.1 \%$ & $2281.5 \%$ \\
\hline $\begin{array}{l}\text { Choosing a different name } \\
\text { corresponding to desired } \\
\text { gender (even if not shared } \\
\text { with others) }\end{array}$ & $\begin{array}{l}36 \\
52.2 \%\end{array}$ & $2047.6 \%$ & $1659.3 \%$ \\
\hline $\begin{array}{l}\text { Changing activities or } \\
\text { pastimes to correspond } \\
\text { with desired gender }\end{array}$ & $34.3 \%$ & $12.4 \%$ & $27.4 \%$ \\
\hline $\begin{array}{l}\text { Asking to be referred to as } \\
\text { the desired gender }\end{array}$ & $\begin{array}{l}28 \\
40.6 \%\end{array}$ & $1433.3 \%$ & $1451.9 \%$ \\
\hline
\end{tabular}

- The reference term, i.e. what is changed: gender, sex, identity, unspecified.

- The change term: trans*, transition, dysphoria, incongruence, other terms.

A majority $(74.6 \%, \mathrm{n}=53)$ mentioned a reference term. Among them, the most frequent one was gender $(66 \%, n=35)$ followed by identity $(30.2 \%, \mathrm{n}=16)$ (Table 4$)$.

The change term most often mentioned was "trans" ( $40.8 \%, \mathrm{n}=29)$, followed by "dysphoria" ( $14.1 \%, \mathrm{n}=10)$ and "transition" $(12.7 \%, \mathrm{n}=9)$.

\section{Discussion}

The current released version of the ICD 11 renamed "transgender identity" to "gender incongruence", removed it from the chapter of mental and behavioral disorders to a new one titled "Conditions related to sexual health", and revised the diagnostic guidelines. The rationale was that psychological distress and functional impairment do not have to be considered diagnostic requirements anymore, and may be associated with social factors such as stigmatisation, rejection, and violence resulting from transgender status and its psychiatrisation. This was initially confirmed by Robles et al. [5] in Mexico, where transgender-related health services are delivered in a Specialised Clinic of a Psychiatric Institute.

Thus, the objectives of the French study were the same as the Mexican study using the same method but within a primary care center. We also wanted to examine whether the use of health services for the transformation of the body was related to distress, dysfunction, and/or rejection and violence. Finally, we questioned participants about their preferred terminology to express the idea of "gender change". 
Table 3

Gender identity features, use of health services for boy transformation, violence and rejection related to distress and dysfunction.

\begin{tabular}{|c|c|c|c|}
\hline & $\begin{array}{l}\text { No distress reported } \\
\mathrm{n}=8 \\
\mathrm{n} \%\end{array}$ & $\begin{array}{l}\text { Distress reported } \\
\mathrm{n}=61 \\
\mathrm{n} \%\end{array}$ & Statistics \\
\hline \multicolumn{4}{|l|}{ Demographics } \\
\hline Current gender identity ${ }^{\mathrm{a}}$ - Male & $112.5 \%$ & $2642.6 \%$ & $\chi_{(1)}^{2}=2.6, p=0.10$ \\
\hline - Female & $787.5 \%$ & $3557.4 \%$ & \\
\hline Marital status - Single & $675.0 \%$ & $4573.8 \%$ & $\chi_{(1)}^{2}=0.006, p=0.94$ \\
\hline Employment status - Remunerated & $562.5 \%$ & 2134.4 & $\chi_{(1)}^{2}=2.3, p=0.12$ \\
\hline Age (years) mean (SD; range) & $32.5(9.8 ; 20-47)$ & $27.1(9.6 ; 18-50)$ & $t_{(67)}=1.4, p=0.14$ \\
\hline Years of education (mean; SD; range) & $13.6(2.2 ; 10-16)$ & $13.8(2.5 ; 9-20)$ & $t_{(67)}=0, p=0.85$ \\
\hline \multicolumn{4}{|l|}{ Discomfort with body aspects and surgeries for body transformation } \\
\hline Surgery for body transformation ${ }^{\mathrm{b}}$ & $450.0 \%$ & $4675.4 \%$ & $\chi_{(1)}^{2}=2.2, p=0.13$ \\
\hline General body changes - Yes & $562.5 \%$ & $4878.7 \%$ & $\chi_{(1)}^{2}=1.0, p=0.30$ \\
\hline Facial and body hair - Yes (assigned men at birth, $n=44$ ) & $228.6 \%$ & $2982.9 \%$ & $\chi_{(1)}^{2}=8.8, p=0.003$ \\
\hline Discomfort with pubic hair - Yes & $225.0 \%$ & $1829.5 \%$ & $\chi_{(1)}^{2}=0.07, p=0.79$ \\
\hline Use of health services for body transformation - Yes & $675.0 \%$ & $5183.6 \%$ & $\chi_{(1)}^{2}=0.36, p=0.54$ \\
\hline Surgery for body transformation ${ }^{\mathrm{b}}-$ Yes $(\mathrm{n}=57)$ & $350.0 \%$ & $2039.2 \%$ & $\chi_{(1)}^{2}=0.2, p=0.61$ \\
\hline \multicolumn{4}{|l|}{ Changes to be more similar to the desired gender } \\
\hline Physical appearance - Yes & $562.5 \%$ & $4777.0 \%$ & $\chi_{(1)}^{2}=0.8, p=0.36$ \\
\hline Dress - Yes & $675.0 \%$ & $4065.6 \%$ & $\chi_{(1)}^{2}=0.2, p=0.59$ \\
\hline Asking to be referred to as the desired gender -Yes & $225.0 \%$ & $2642.6 \%$ & $\chi_{(1)}^{2}=0.9, p=0.34$ \\
\hline \multicolumn{4}{|l|}{ Experiences of rejection and violence } \\
\hline Experienced rejection - Yes & $337.5 \%$ & $3557.4 \%$ & $\chi_{(1)}^{2}=1.1, p=0.28$ \\
\hline From family - Yes & $225.0 \%$ & $2032.8 \%$ & $\chi_{(1)}^{2}=0.1, p=0.65$ \\
\hline Rejection from friends - Yes & $112.5 \%$ & $914.8 \%$ & $\chi_{(1)}^{2}=0.02, p=0.86$ \\
\hline From schoolmates/coworkers - Yes & $112.5 \%$ & $2642.6 \%$ & $\chi_{(1)}^{2}=2.6, p=0.10$ \\
\hline Experienced violence - Yes & $225.0 \%$ & $3049.2 \%$ & $\chi_{(1)}^{2}=1.6, p=0.19$ \\
\hline Physical -Yes & $112.5 \%$ & $1626.2 \%$ & $\chi_{(1)}^{2}=0.7, p=0.39$ \\
\hline Psychological -Yes & $225.0 \%$ & $3049.2 \%$ & $\chi_{(1)}^{2}=1.6, p=0.19$ \\
\hline Sexual -Yes & - & $914.8 \%$ & $\chi_{(1)}^{2}=1.3, p=0.24$ \\
\hline Economic -Yes & $112.5 \%$ & $711.5 \%$ & $\chi_{(1)}^{2}=0.007, p=0.93$ \\
\hline \multicolumn{4}{|l|}{ Dysfunction level of intensity (0 à 10) } \\
\hline Family dysfunction $^{\mathrm{a}}$ & $1.7(2.3 ; 0-6)$ & $3.6(3.6 ; 0-10)$ & $t_{(67)}=1.3, p=0.16$ \\
\hline Social dysfunctionl ${ }^{\mathrm{a}}$ & $3.3(3.7 ; 0-9)$ & $5.4(3.3 ; 0-10)$ & $t_{(67)}=1.6, p=0.10$ \\
\hline \multirow[t]{2}{*}{ Work and scholastic dysfunction ${ }^{\mathrm{a}}$} & $2.6(4.3 ; 0-10)$ & $5.2(3.1 ; 0-10)$ & $t_{(67)}=2.1 p=0.03$ \\
\hline & $\begin{array}{l}\text { No dysfonction reported } \\
\mathrm{n}=10 \\
\mathrm{n} \%\end{array}$ & $\begin{array}{l}\text { Reported dysfunction } \\
n=59 \\
n \%\end{array}$ & Statistics \\
\hline \multicolumn{4}{|l|}{ Demographics } \\
\hline Current gender identity ${ }^{\mathrm{a}}$ - Male & $330.0 \%$ & $2440.7 \%$ & $\chi_{(1)}^{2}=0.4, p=0.52$ \\
\hline - Female & $770.0 \%$ & $3559.3 \%$ & \\
\hline Marital status - Single & $880.0 \%$ & $4372.9 \%$ & $\chi_{(1)}^{2}=0.2, p=0.63$ \\
\hline Employment status - Remunerated & $550.0 \%$ & $2135.6 \%$ & $\chi_{(1)}^{2}=0.7, p=0.38$ \\
\hline Age (years) mean (SD; range) & $29.7(9.4 ; 20-47)$ & $27.4(9.8 ; 18-50)$ & $t_{(67)}=0.6, p=0.50$ \\
\hline Years of education mean(SD; range) & $14.3(2.4 ; 10-17)$ & $13.6(2.5 ; 9-20)$ & $t_{(67)}=0.84, p=0.48$ \\
\hline \multicolumn{4}{|l|}{ Discomfort with body aspects and surgeries for body transformation } \\
\hline Genitals - Yes & $880.0 \%$ & $4271.2 \%$ & $\chi_{(1)}^{2}=0.3, p=0.56$ \\
\hline General body changes - Yes & $770.0 \%$ & $4678.0 \%$ & $\chi_{(1)}^{2}=0.3, p=0.58$ \\
\hline Facial and body hair - Yes (assigned men at birth, $n=44$ ) & $457.1 \%$ & $2777.1 \%$ & $\chi_{(1)}^{2}=1.2, p=0.27$ \\
\hline Discomfort with pubic hair - Yes & $330.0 \%$ & 1728.8 & $\chi_{(1)}^{2}=0.006, p=0.93$ \\
\hline Use of health services for body transformation - Yes & $770.0 \%$ & 5084.7 & $\chi_{(1)}^{2}=1.2, p=0.25$ \\
\hline Surgery for body transformation-Yes $(n=57)$ & $342.9 \%$ & 2040.0 & $\chi_{(1)}^{2}=0.02, p=0.88$ \\
\hline \multicolumn{4}{|l|}{ Changes to be more similar to the desired gender } \\
\hline Physical appearance -Yes & $770.0 \%$ & $4576.3 \%$ & $\chi_{(1)}^{2}=0.1 p=0.67$ \\
\hline Dress - Yes & $990.0 \%$ & $3762.7 \%$ & $\chi_{(1)}^{2}=2.8, p=0.09$ \\
\hline Asking to be referred to as the desired gender - Yes & $330.0 \%$ & $2542.4 \%$ & $\chi_{(1)}^{2}=0.5, p=0.46$ \\
\hline \multicolumn{4}{|l|}{ Experiences of rejection and violence } \\
\hline Experienced rejection - Yes & $220.0 \%$ & $3661.0 \%$ & $\chi_{(1)}^{2}=5 ., p=0.01$ \\
\hline From family - Yes & $110.0 \%$ & $2135.6 \%$ & $\chi_{(1)}^{2}=2.5, p=0.10$ \\
\hline From friends - Yes & $220.0 \%$ & $813.6 \%$ & $\chi_{(1)}^{2}=0.2, p=0.59$ \\
\hline From schoolmates/coworkers - Yes & - & $2745.8 \%$ & $\chi_{(1)}^{2}=7.5, p=0.006$ \\
\hline Experienced violence - Yes & $220.0 \%$ & $3050.8 \%$ & $\chi_{(1)}^{2}=3.2, p=0.07$ \\
\hline Physical - Yes & $110.0 \%$ & $1627.1 \%$ & $\chi_{(1)}^{2}=1.3, p=0.24$ \\
\hline Psychological - Yes & $220.0 \%$ & $3050.8 \%$ & $\chi_{(1)}^{2}=3.2, p=0.07$ \\
\hline Sexual - Yes & - & $915.3 \%$ & $\chi_{(1)}^{2}=1.7, p=0.18$ \\
\hline Economic - Yes & - & $813.6 \%$ & $\chi_{(1)}^{2}=1.5, p=0.21$ \\
\hline
\end{tabular}

Demographics

Current gender identity ${ }^{\mathrm{a}}$ - Male

- Female

No use of health services for body transformation $\mathrm{n}=12$

n \%
Use of health services for body transformation

$\mathrm{n}=57$

n \% $=57$
$325.0 \%$

$2442.1 \%$

$975.0 \%$

$3357.9 \%$

Statistics

-


Table 3 (Continued)

\begin{tabular}{|c|c|c|c|}
\hline & $\begin{array}{l}\text { No use of health services for body } \\
\text { transformation } \\
n=12 \\
n \%\end{array}$ & $\begin{array}{l}\text { Use of health services for body } \\
\text { transformation } \\
\mathrm{n}=57 \\
\mathrm{n} \%\end{array}$ & Statistics \\
\hline Marital status --Single & $866.7 \%$ & $4375.4 \%$ & $\begin{array}{l}\chi_{(1)}^{2}=0.3 \\
p=0.52\end{array}$ \\
\hline Employment status - Remunerated & $18.3 \%$ & $2543.9 \%$ & $\begin{array}{l}\chi^{2}(1)=5.3 \\
p=0.02\end{array}$ \\
\hline Age (years) mean (SD; range) & $2(0 ; 9.6 ; 21-48)$ & $27.7(9.9 ; 18-50)$ & $\begin{array}{l}t_{(67)}=0.09 \\
p=0.92\end{array}$ \\
\hline Years of education mean (SD; range) & $14.4(2.8 ; 10-20)$ & $13.6(2.4 ; 9-18)$ & $\begin{array}{l}t_{(67)}=0.9 \\
p=0.34\end{array}$ \\
\hline \multicolumn{4}{|l|}{ Discomfort with body aspects } \\
\hline Genitals - Yes & $866.7 \%$ & $4273.7 \%$ & $\begin{array}{l}\chi_{(1)}^{2}=0.2 \\
p=0.62\end{array}$ \\
\hline General body changes - Yes & $975.0 \%$ & $4477.2 \%$ & $\begin{array}{l}\chi^{2}(1)=0.02 \\
p=0.87\end{array}$ \\
\hline Facial and body hair - Yes (assigned men at birth, $n=42$ ) & $777.8 \%$ & $2472.7 \%$ & $\begin{array}{l}\chi^{2}(1)=0.09 \\
p=0.76\end{array}$ \\
\hline Discomfort with pubic hair - Yes & $325.0 \%$ & $1729.8 \%$ & $\begin{array}{l}\chi^{2}(1)=0.1 \\
p=0.73\end{array}$ \\
\hline \multicolumn{4}{|l|}{ Changes to be more similar to the desired gender } \\
\hline Physical appearance - Yes & $975.0 \%$ & $4375.4 \%$ & $\begin{array}{l}\chi_{(1)}^{2}=0.001 \\
p=0.97\end{array}$ \\
\hline Dress - Yes & $758.3 \%$ & $3968.4 \%$ & $\begin{array}{l}\chi 2(1)=0.4 \\
p=0.50\end{array}$ \\
\hline Asking to be referred to as the desired gender - Yes & $18.3 \%$ & $2747.4 \%$ & $\begin{array}{l}\chi^{2}(1)=6.2 \\
p=0.01\end{array}$ \\
\hline \multicolumn{4}{|l|}{ Experiences of rejection and violence } \\
\hline Experienced rejection - Yes & $758.3 \%$ & $3154.4 \%$ & $\begin{array}{l}\chi_{(1)}^{2}=0.06 \\
\mathrm{p}=0.80\end{array}$ \\
\hline From family - Yes & $216.7 \%$ & $2035.1 \%$ & $\begin{array}{l}\chi^{2}(1)=1.5 \\
p=0.21\end{array}$ \\
\hline From friends -Yes & $18.3 \%$ & $915.8 \%$ & $\begin{array}{l}\chi^{2}(1)=0.4 \\
p=0.50\end{array}$ \\
\hline From schoolmates/coworkers - Yes & $433.3 \%$ & $2340.4 \%$ & $\begin{array}{l}\chi^{2}(1)=0.2 \\
p=0.65\end{array}$ \\
\hline Experienced violence - Yes & $541.7 \%$ & $2747.4 \%$ & $\begin{array}{l}\chi^{2}(1)=0.1 \\
p=0.71\end{array}$ \\
\hline Physical - Yes & $216.7 \%$ & $1526.3 \%$ & $\begin{array}{l}\chi^{2}(1)=0.4 \\
p=0.48\end{array}$ \\
\hline Psychological violence - Yes & $541.7 \%$ & $2747.4 \%$ & $\begin{array}{l}\chi^{2}(1)=0.1 \\
p=0.71\end{array}$ \\
\hline Sexual violence - Yes & - & $915.8 \%$ & $\begin{array}{l}\chi^{2}(1)=2.1 \\
p=0.14\end{array}$ \\
\hline Economic violence - Yes ${ }^{\mathrm{a}}$ & $18.3 \%$ & $712.3 \%$ & $\begin{array}{l}\chi^{2}(1)=0.1 \\
p=0.69\end{array}$ \\
\hline \multicolumn{4}{|l|}{ Dysfunction level of intensity ( 0 à 10 ) } \\
\hline Family $^{\mathrm{a}}$ & $3.4(3.4 ; 0-10)$ & $3.3(3.6 ; 0-10)$ & $\begin{array}{l}t_{(67)}=0.02 \\
p=0.97\end{array}$ \\
\hline Social $^{\mathrm{a}}$ & $6.0 ; 3.4 ; 0-10$ & $5.0(3.4 ; 0-10)$ & $\begin{array}{l}t_{(67)}=0.8, p= \\
0.38\end{array}$ \\
\hline Work and scholastic ${ }^{\mathrm{a}}$ & $5.0(3.2 ; 0-9)$ & $4.8(3.3 ; 0-10)$ & $\begin{array}{l}t_{(67)}=0.09 \\
p=0.92\end{array}$ \\
\hline
\end{tabular}

a Based on adaptation of the Sheehan Disability Scale (1996).

Approximately half participants reported social rejection, mostly by classmates or colleagues, and family members. They also experienced violence during their adolescence, primarily psychological in nature.

\section{Table 4}

Appropriate words ( $\mathrm{n}$ \% \%) to rephrase gender change, as a function of reference and change terms $(n=71)$.

\begin{tabular}{llllll}
\hline \multirow{2}{*}{ Change Term } & \multicolumn{2}{l}{ Reference term } & \multirow{2}{*}{ Total } \\
\cline { 2 - 5 } & Gender & Sex & Identity & unspecified & \\
\hline Trans & $1521.1 \%$ & $22.8 \%$ & $1115.5 \%$ & $11.4 \%$ & $2940.8 \%$ \\
Transition & $22.8 \%$ & - & - & $79.9 \%$ & $912.7 \%$ \\
Dysphoria & $811.3 \%$ & - & - & $22.8 \%$ & $1014.1 \%$ \\
Incongruence & $11.4 \%$ & - & - & $11.4 \%$ & $22.8 \%$ \\
Other & $912.7 \%$ & - & $57 \%$ & $79.9 \%$ & $2129.6 \%$ \\
Total & $3549.3 \%$ & $22.8 \%$ & $1622.5 \%$ & $1825.4 \%$ & \\
\hline
\end{tabular}

Note: Some participants did not answer the question and others gave multiple answers.
More importantly, most of them, but not all of them, reported having experienced psychological distress and dysfunction. Moreover, reported violence, especially from schoolmates, and level of work and/or scholastic rejection, were higher when participants experienced dysfunction.

The use of health services was unrelated to distress, dysfunction, and/or rejection and violence.

A observed in Robles's study [5], distress and dysfunction were not always reported by transgender people and thus, should not be required for the diagnosis. It supports the placement of transgenderism outside the category of "Mental and Behavioral Disorders". Nevertheless, we ought to remember that depsychiatrisation does not mean demedicalisation. The protocol initiated by the MDS shows that it is possible to care for transgender people without requiring a psychiatric diagnosis. This contributes to shorten the transition process and make it easier to live with. 
Another important question relates to the phrasing of the diagnosis. Even if "sex" and "gender" are replaced by "assigned sex" and "experienced gender", the definitions do not incorporate the idea that some people define themselves as "variant", and describe change as a process rather than in binary terms. Results showed that a majority of participants suggested the use of the prefix "trans" or the word "transition", instead of "incongruence" or "dysphoria", arguing against a binary conception. Moreover, these results question whether the ICD should refer to the person, their state until their transition, or to the transition process itself.

The study presents some shortcomings. First, participants were recruited on a voluntary basis in a specific health service. Thus, the results might not be representative of the French transgender population. What is most important is to observe that the relation between social environment and distress or dysfunction does not appear to depend on country [5,6,29]. Moreover, the study is an opportunity to show that medical care of transgender people can be offered without requiring a psychiatric diagnosis.

Secondly, for statistical reasons, the analyses could not include people who identified as "queer" due to their low number $(n=3)$, probably resulting from the choice of the MDS as the research site. Consequently, these results might not reflect the reality of their experience and future research should close this gap in knowledge. In the meantime, future ICD definitions should take this reality into account and be as inclusive as possible in regards to people who identify outside of binary gender.

Finally, one may object that data are based on retrospective interviews. However, while often influenced by emotional context, this procedure is largely used in social psychological studies on the self and autobiographic memory [30].

Despite these limitations, one can hope that depsychiatrisation of transgenderism will transfer the standards by which we decide who can receive medical care away from mental health diagnoses in favor of human rights. This is especially relevant in France where transgender people can begin their transition, including legally changing their gender, before resorting to the health care system.

\section{Conclusion}

Results do not support a psychiatric or binary conception of transgenderism. Psychological distress and functional impairment were not reported by every participant, and may result from rejection and violence coming from coworkers and schoolmates. This should be conveyed by the chosen label for ICD-11 and therefore questions the proposition of "gender incongruence".

Moreover, labeling and defining the diagnosis should not be limited to the medical point of view but should also take into account human rights, and cultural, linguistic, legal, and social perspectives.

\section{Acknowledgements}

1. The present study received financial support from the Direction Générale de la Santé (DGS), and the Maison Dispersée de Santé (MDS).

2.The authors are grateful to Dr Riff for his availability and kind help, to transgender people who agreed to participate in the pretest and the study, as well as to the transgender associations who have all made contributions to this study (Association Nationale Transgenre (ANT); Association Beaumont Continental (ABC); C'est Pas Mon Genre; J'en suis - j'y reste; En-Trans; Espace Santé Trans (EST).

The authors would also like to thank Patrice Desmons (CCOMS, France) for his deep involvement in the elaboration of the protocol, Silvia d'Oca (University of Cagliari, Italy) for her help on additional questions analysis, and Brian Hofer for proofreading.

\section{References}

[1] Cruz TM. Assessing access to care for transgender and gender nonconforming people: a consideration of diversity in combating discrimination. Soc Sci Med 2014;110:65-73, doi:http://dx.doi.org/10.1016/j.socscimed.2014.03.032.

[2] Lev AI. Disordering gender identity. J Psychol Human Sex 2006;17:35-69, doi: http://dx.doi.org/10.1300/J056v17n03_03.

[3] Thomas M. Pour un cadre générique du transsexualisme. Inf Psychiatr 2011;87:301-4, doi:http://dx.doi.org/10.1684/ipe.2011.0775.

[4] Thomas M-Y, Espineira K. Le « transsexualisme », entre normes sociojuridiques, normes de santé et normes de genre. Nouv Prat Soc 2016;28:34, doi:http://dx. doi.org/10.7202/1039172ar.

[5] Robles R, Fresán A, Vega-Ramírez H, Cruz-Islas J, Rodríguez-Pérez V, et al. Removing transgender identity from the classification of mental disorders: a Mexican field study for ICD-11. Lancet Psychiatry 2016;3:850-9, doi:http://dx. doi.org/10.1016/S2215-0366(16)30165-1.

[6] Campbell MM, Fresán A, Addinall RM, Böhmke W, Grobler GP, Marais A, et al. Experiences of gender incongruence and the relationship between social exclusion, psychological distress, and dysfunction among South African transgender adults: a field-study for ICD-11. Ann Clin Psychiatry 2018;30:168-74.

[7] Drescher J, Cohen-Kettenis P, Winter S. Minding the body: situating gender identity diagnoses in the ICD-11. Int Rev Psychiatry 2012;24:568-77, doi: http://dx.doi.org/10.3109/09540261.2012.741575.

[8] Reed GM, Drescher J, Krueger RB, Atalla E, Cochran SD, First MB, et al. Disorders related to sexuality and gender identity in the ICD-11: revising the ICD-10 classification based on current scientific evidence, best clinical practices, and human rights considerations. World Psychiatry 2016;15:205-21, doi:http://dx doi.org/10.1002/wps.20354.

[9] Drescher J. Controversies in gender diagnoses. J LGBT Health 2014;1:10-4, doi: http://dx.doi.org/10.1089/lgbt.2013.1500.

[10] Reucher T. Dépsychiatriser sans démédicaliser, une solution pragmatique. Inf Psychiatr 2011;87:295-9, doi:http://dx.doi.org/10.1684/ipe.2011.0774.

[11] Reed GM. Vers la CIM-11 : créer un espace pour une diversité de perspectives. Inf Psychiatr 2011;87:169, doi:http://dx.doi.org/10.3917/inpsy.8703.0169.

[12] Reed GM. Vers la CIM-11 : créer un espace pour une diversité de perspectives Inf Psychiatr 2011;87:169, doi:http://dx.doi.org/10.3917/inpsy.8703.0169.

[13] Schembri D. Discrimination against transgender people in Europe - Report of the Committee on Equality and Non-Discrimination. 2015.

[14] SOS Homophobie. Rapport sur l'homophobie 2018. 2018.

[15] Hughto JMW, Reisner SL, Pachankis JE. Transgender stigma and health: a critical review of stigma determinants, mechanisms, and interventions. Soc Sci Med 2015;147:222-31, doi:http://dx.doi.org/10.1016/j.socscimed.2015.11.010.

[16] Frost DM, Lehavot K, Meyer IH. Minority stress and physical health among sexual minority individuals. Springer; 2013, doi:http://dx.doi.org/10.1007/ s10865-013-9523-8.

[17] Rood BA, Reisner SL, Surace FI, Puckett JA, Maroney MR, Pantalone DW. Expecting rejection: understanding the minority stress experiences of transgender and gender-nonconforming individuals. Transgender Health 2016;1:151-64, doi:http://dx.doi.org/10.1089/trgh.2016.0012.

[18] Miller CT, Major B. Coping with stigma and prejudice. In: Heattheron TD, Kleck RE Hebl MR, Hull JG, editors. Soc. Psychol. Stigma. Guilford Press; 2000. p. 243-72.

[19] De la Chenelière $\mathrm{M}$. De patient à chercheur : parcours d'empowerment autour de la transidentité. Inf Psychiatr n.d.

[20] World Professional Association for Transgender Health. Standards of care for the health of transsexual, transgender and gender non-conforming people 7th version. , doi:http://dx.doi.org/10.1080/15532739.2011.700873.

[21] De Cuypere G, Jannes C, Rubens R. Psychosocial functioning of transsexuals in Belgium. Acta Psychiatr Scand 1995;91:180-4, doi:http://dx.doi.org/10.1111/ j.1600-0447.1995.tb09763.x.

[22] Zucker KJ, Bradley SJ, Owen-Anderson A, Kibblewhite SJ, Wood H, Singh D, et al. Demographics, behavior problems, and psychosexual characteristics of adolescents with gender identity disorder or transvestic fetishism. J Sex Marital Ther 2012;38:151-89, doi:http://dx.doi.org/10.1080/ 0092623X.2011.611219.

[23] Carroll RA. Outcomes of treatment for gender dysphoria. J Sex Educ Ther 1999;24:128-36, doi:http://dx.doi.org/10.1080/01614576.1999.11074292.

[24] Seil D. The diagnosis and treatment of transgendered patients. J Gay Lesbian Ment Health 2004;8:99-116, doi:http://dx.doi.org/10.1080/ 19359705.2004 .9962369$.

[25] Roelandt J-L, Askevis-Leherpeux F, Desmons P, De la Chenelière M. 11th revision of the international classification of diseases: toward ICD-11 categories on gender incongruence: evaluation of validity, reliability and utility of proposals among transgender people. 2018.

[26] Espineira K. Le bouclier thérapeutique : discours et limites d' un appareil de légitimation. Rev Int Rech Biogr 2011;189-201.

[27] Steensma TD, Biemond R, De Boer F, Cohen-Kettenis PT. Desisting and persisting gender dysphoria after childhood: a qualitative follow-up study. Clin Child Psychol Psychiatry 2011;16:499-516, doi:http://dx.doi.org/10.1177/ 1359104510378303

[28] Sheehan DV. The anxiety disease. Charles Scribner's Sons; 1983.

[29] Robles R. ICD-11 field studies on gender incongruence: evidence from African, Arab, European and Latin American countries for removing transgender categories from the chapter on mental disorders. Eur Congr Psychiatry 2018.

[30] Baumeister RF. The self. In: Gilbert DT, Fiske ST, Lindzey G, editors. Handb. Soc. Psychol.. . p. 680-740. 